\title{
Histopathology and cytopathology of white spot syndrome virus (WSSV) in cultured Penaeus monodon from peninsular Malaysia with emphasis on pathogenesis and the mechanism of white spot formation
}

\author{
Y. G. Wang*, M. D. Hassan, M. Sharifi, S. M. Zamri, X. Chen \\ Faculty of Veterinary Medicine, Universiti Putra Malaysia 43400 UPM, Serdang, Selangor, Malaysia
}

\begin{abstract}
Since 1994, white spot syndrome virus (WSSV) has been detected in cultured shrimp Penaeus monodon in Peninsular Malaysia. The gross signs, target organs and histo-cytopathology for the viral infection were studied and it was found to infect most organs and tissues including oocytes, but not hepatopancreatocytes and epithelial cells of the midgut, which were regarded as refractory tissues. Based on a time-sequence of ultrastructural cytopathology, 4 cytopathic profiles and 6 phases of viral morphogenesis were described. The virions were elliptical to short rods with trilamilar envelopes that measured $305 \pm 30 \times 127 \pm 11 \mathrm{~nm}$. Viral nucleosomes were often present singly in infected nuclei and were associated with the early stages of viral replication. The structure of WSSV pathognomonic white, cuticular lesions was examined at the microscopic and ultrastructural levels and the mechanism of their formation appeared to be related to the disruption of exudate transfer from epithelial cells to the cuticle via cuticular pore canals.
\end{abstract}

KEY WORDS: Shrimp - Penaeus monodon - White spot syndrome virus - Histopathology · Pathogenesis Viral nucleosome. White spot formation

\section{INTRODUCTION}

Since 1992, a syndrome commonly referred as 'white spot disease' (WSD) or 'white spot syndrome' (WSS) has overshadowed all other diseases causing major losses of cultured shrimp in Asia (Takahashi et al. 1994, Wang et al. 1995, Flegel et al. 1996). The disease is characterised by distinct white spots in the cuticle, lethargy with cumulative mortalities often reaching $100 \%$ within 2 to $7 \mathrm{~d}$ (Chou et al. 1995, Huang et al. 1995, Wongteerasupaya et al. 1995). Although, the causative agents of WSD (enveloped, non-occluded, rod-shaped DNA viruses) have been reported from different geographic locations under different names, they appear to be very similar in terms of gross signs of disease, histopathology, morphology and genome structure (Flegel 1997). Indeed, they have been reported to

·E-mail: wangyingeng@hotmail.com give positive cross reactions by both in situ hybridization (Wongteerasupaya et al. 1996) and polymerase chain reaction (PCR) (Kasornchandra \& Boonyaratpalin 1996). Therefore, they are increasingly considered to be the same virus or different strains of it and they are grouped as white spot syndrome baculovirus (WSSV) (Lightner 1996, Durand et al. 1997). Recently, the abbreviation WSSV has been widely used to stand for white spot syndrome virus (i.e. the 'baculo' prefix has been dropped) since the relationship of the virus to baculoviruses is now questioned (Kasornchandra \& Boonyaratpalin 1998)

Over the past several years, the Malaysian shrimp industry has experienced massive losses in both hatcheries and grow-out ponds. With the intensification of culture, diseases began to appear more frequently from the early 1990s onward and they have become one of the major deterrents to achieving maximum production in shrimp farming. In 1994, shrimp farmers in the 
State of Kedah in North Malaysia lost 4 to 8 million US\$ due to disease problems (Shariff 1995). Recently, WSD has spread rapidly to shrimp farms across several states along the coast of Peninsular Malaysia. We first reported WSD in Malaysia in 1994 with a prevalence of $23 \%$ in Penaeus monodon grow-out farms. It was regarded as an exotic introduction from Thailand through importation of postlarvae (Wang et al. 1996). By 1995,40 to $50 \%$ of farms were affected and by the end of 1996 , the disease was found in $80 \%$ of farms (Wang et al. in press). This paper presents results from our investigations on the histo-cytopathology of WSD in Malaysia with emphasis on its pathogenesis and mechanism of white spot formation.

\section{MATERIALS AND METHODS}

About 50 live specimens of apparently healthy and diseased Penaeus monodon were examined from each of 12 grow-out farms along the coast of Peninsular Malaysia from 1994 to 1996 . These specimens could be categorized into 2 groups. One group comprised specimens pooled from several of our field investigations, while the other group consisted of pooled specimens submitted by farmers to our laboratory for the diagnosis of WSS. Gross signs recorded were based on case histories from the field and general inspections including wet mount microscopy in the laboratory. For histopathology, 20 to 30 shrimp from each collection were preserved in Davidson's fixative for 48 to $72 \mathrm{~h}$ (large shrimp were first injected with the fixative) and then processed routinely. Sections of paraffin embedded tissue were cut at $5 \mu \mathrm{m}$ and stained with modified Mayer's hematoxylin and eosin/phloxine (H\&E/phloxine) stains (Bell \& Lightner 1988, Lightner 1996).

For time-lapse study of WSSV pathogenesis, a group of grossly healthy shrimp (not showing gross signs of WSS and negative by Dot Blot Hybridization [DiagXotics, Inc. USA] for WSSV, but positive for WSSV by nested PCR) were obtained from 2 farms. These shrimp were maintained in laboratory aquaria, and monitored closely. Five shrimp were sampled daily for histopathology and another 5 for ultrastructural cytopathology during the 5 to $6 \mathrm{~d}$ course of worsening WSSV disease. Sequential changes in gross signs were recorded by noting the daily progression of lesions and abnormal behavior.

To prepare ultrathin sections for transmission electron microscopy (TEM), diced tissues from the shrimp were fixed overnight with $4 \%$ glutaraldehyde in $0.2 \mathrm{M}$ cacodylate phosphate buffer ( $\mathrm{pH} 7.4$ ) at $4^{\circ} \mathrm{C}$, and postfixed with $1 \%$ osmium tetroxide for $2 \mathrm{~h}$. The tissues were then dehydrated in a graded acetone series and embedded in resin mixture. Ultrathin sections at 70 to $90 \mathrm{~nm}$ were cut and stained with uranyl acetate and lead citrate (Hayat 1986). White spot foci (including the cuticle and associated cuticular epidermis) were decalcified before being fixed in $1 \%$ osmium tetroxide. For decalcification, the tissues were immersed in a mixture of formic acid (25 ml), $25 \%$ glutaraldehyde $(2 \mathrm{ml})$ and distilled water $(100 \mathrm{ml})$ for $12 \mathrm{~h}$, followed by transfer to $70 \%$ alcohol for $12 \mathrm{~h}$ and finally to $0.1 \mathrm{M}$ cacodylate buffer twice (4 h each).

\section{RESULTS}

\section{Gross pathology}

White spots first appeared on the carapace and on the fifth-sixth abdominal segments, and later on the shell of the whole body. Sizes of the spots varied from barely visible dots to spots of $3 \mathrm{~mm}$ in diameter (Fig. 1a bottom). The initial microscopic spots mainly appeared as separate tiny dots but they were sometimes also arranged in bead-like order (Fig. 1b). Grossly visible white spots were usually rounded and consisted of a peripheral whitish-brown ring enclosing a brownish central area demarcated by small cavities assembled in bead-like rows. Numerous scattered melanized spots and cavities were found in the central area (Fig. 1c). The spots appeared yellowish-brown and opaque under the microscope rather than white as seen by the naked eye. They were mainly embedded in the cuticle but some portions extended to its inner surface. Large, whitish patches visible to the naked eye also occurred when the spots enlarged and coalesced, resulting in an overall whitish discoloration of the shell (Fig 1a top).

Other signs of the disease included the following: (1) the cuticle could be easily separated from the underlying epidermis; (2) the hepatopancreas (HP) became yellowish-white and was enlarged and fragile; (3) the hemolymph was thin and delayed or failed to coagulate; (4) the shrimp reduced feed intake or stopped feeding, followed by reduction in preening activity and locomotion, which were manifested by gill fouling and a weak response to stimulation, respectively; (5) moribund shrimp usually showed reddish coloration of the body, and they stayed at the pond edge or swam slowly at the water surface before finally sinking to the pond bottom; (6) high mortality rates of 70 to $100 \%$ usually occurred within a week after the emergence of gross signs.

\section{Histopathology by light microscopy}

Tissue sections of affected shrimps stained with $\mathrm{H} \& \mathrm{E}$ /phloxine showed that the virus infected the gills, lymphoid organs, hematopoietic tissue, foregut (including the stomach), cuticular epidermis (Fig. 2a), 


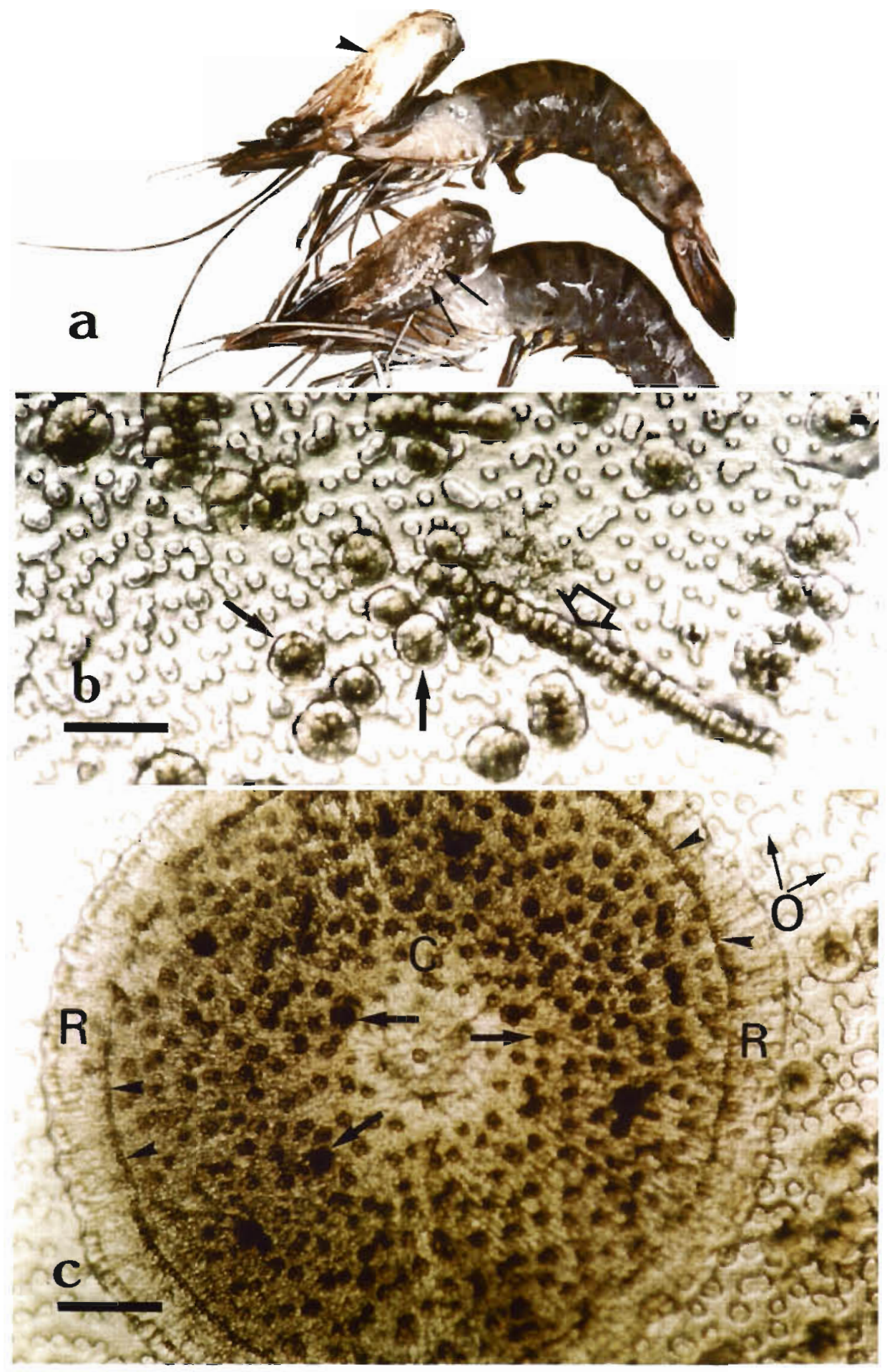

Fig. 1. Gross and microscopic views of white cuticular inclusions characteristic of WSSV infection. (a) WSSV-infected Penaeus monodon. Top: An intact carapace with large whitish patches (arrowhead) embedded in the shell. Bottom: A separated carapace to demonstrate white spots (arrows) embedded in the cuticle. (b) The initial spots appear mainly as small, separate dots (arrows), sometimes arranged in bead-like fashion (open arrow). Wet mount. Scale bar $=215 \mu \mathrm{m}$. (c) Wet mount of cuticle with a white spot under the light microscope, demonstrating a round white inclusion consisting of a peripheral whitish-brown ring (R) and a brownish central area (C) demarcated by small cavities assembled in bead-like rows (arrowheads). The central area contains many scattered melanized dots (arrows) and cavities. Note the openings of tegumental gland ducts (O) present in the normal area of the cuticle. Scale bar $=215 \mu \mathrm{m}$ 


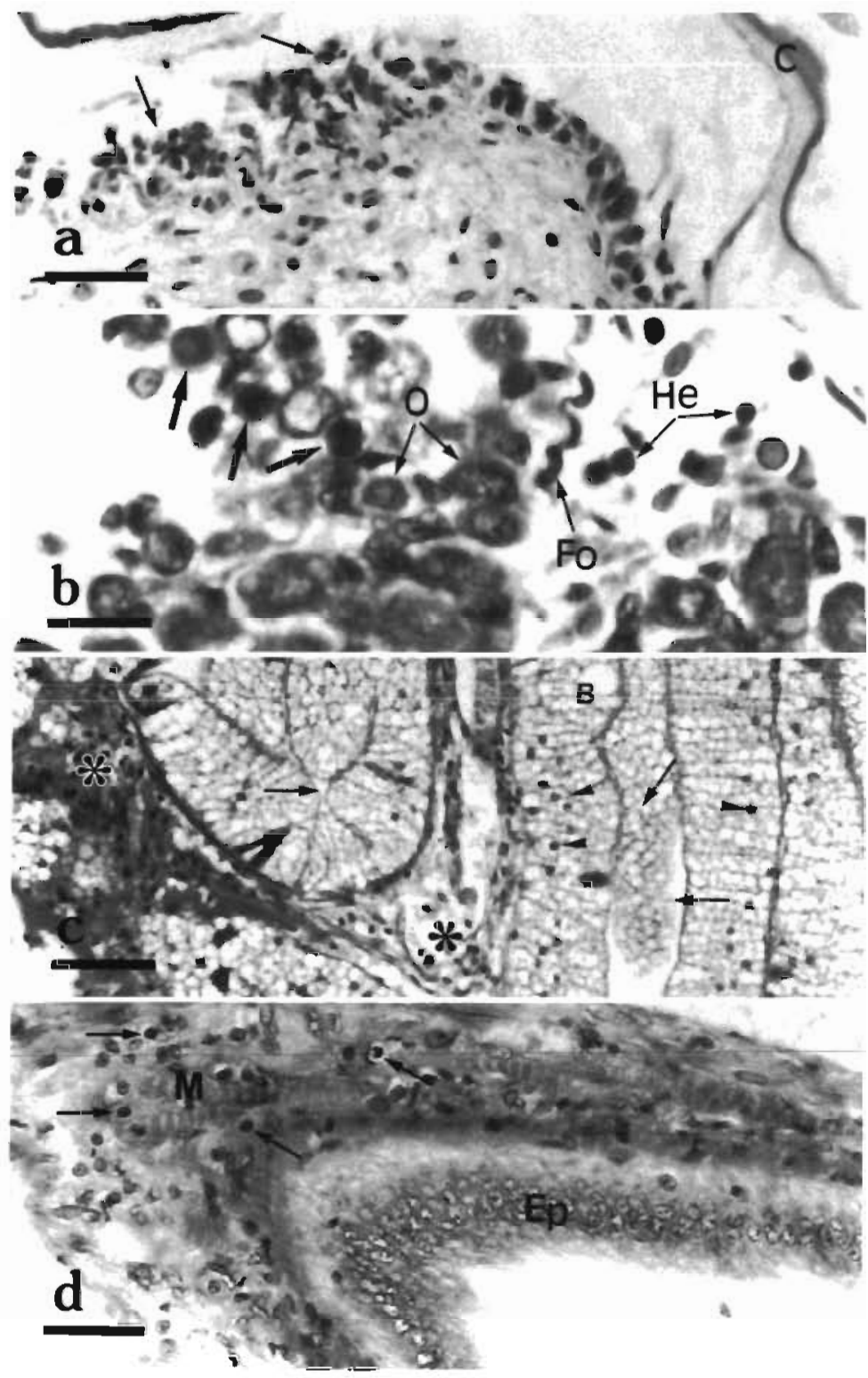

Fig. 2. Histopathology of H\&E/phloxine-stained tissues from moribund Penaeus monodon infected with WSSV. (a) Necrotic cuticular epidermal cells collapsed from the epithelial lining (arrows). Cuticle (C). Scale bar $=43 \mu \mathrm{m}$. (b) Section of ovary showing infected oocytes, follicle cells (Fo) and haemocytes (He). Mildly affected oocytes (O) show deteriorated nuclei with reduced yolk, while dense inclusions (arrows) are formed in heavy infections. Scale bar $=17 \mu \mathrm{m}$. (c) Hepatopancreatic epithelial cells (HECs, arrowheads) show no viral infection, but haemocytes (asterisks) in the hepatopancreas (HP) are heavily infected. HECs are highly vacuolated, resulting in diminution of the tubule lumens (arrows). B-cells (B) are rarely seen. Scale bar = $85 \mu \mathrm{m}$. (d) Both circular and longitudinal muscles (M) of the midgut are infected (arrows), but not epithelial cells (Ep). Scale bar $=43 \mu \mathrm{m}$

connective tissue, striated muscle, heart, haemocytes, antennal gland, nervous tissue and the ovary (Fig. 2b). However, in no case did the virus infect the hepatopancreatic epithelial cells (HEC) or the midgut epithelial cells (MEC), even in moribund specimens (Figs, 2c,d). The HEC showed marked cellular vacuolization that resulted in diminution of the tubular lumens. Meanwhile, it was difficult to find B-cells that normally contain a single large vacuole. Although there were no viral inclusions in $\mathrm{HEC}$, haemocytes in the enlarged hemal sinuses and interstitial spaces of the HP were highly infected (Fig. 2c). The infection of haemocytes was evidenced by the cellular changes such as nuclear hypertrophy, chromatin margination and homogeneous eosinophilic to dense basophilic intranuclear inclusions.
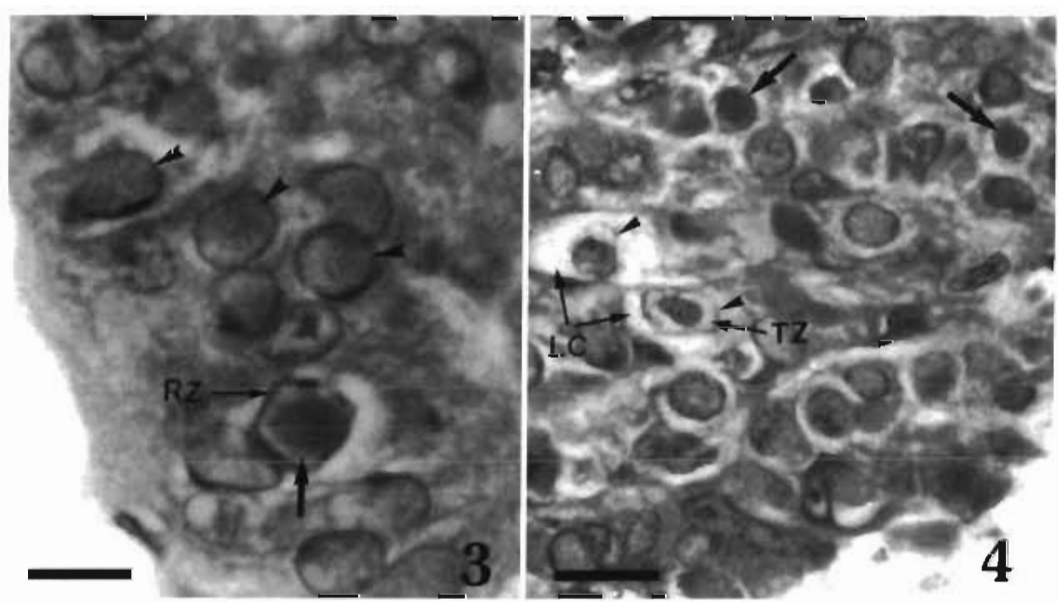

Fig. 3. H\&E/Phloxine staining of the stomach wall of Penaeus monodon infected with WSSV Early infection is characterised by nuclear hypertrophy, nucleolus dissolution, chromatin margination and rarefaction of the central area that appears homogeneous and eosinophilic (arrowheads). Note an eosinophilic Cowdry Atype inclusion (arrow) and the chromatin marginated into a ring-zone (RZ). Scale bar $=9 \mu \mathrm{m}$

Fig. 4. A multifocally infected stomach wall of Penaeus monodon showing a loose and disorganised appearance. The infected cells have lightly basophilic intranuclear inclusions (arrows), while the nuclear membranes are disrupted (arrowheads) at later stages of infection. Note the transparent zone (TZ) and lucent cytoplasm (LC). H\&E/Phloxine, Scale bar $=17 \mu \mathrm{m}$ 
Histopathological observations re vealed that cellular changes upon viral infection were similar in all target tissues. In the early stages of infection, susceptible cells showed nuclear hypertrophy, nuclealar dissolution, chromatin margination and transformation of the central area into a homogeneous eosinophilic region (Fig. 3). The infected cells then progressed to an intranuclear eosinophilic Cowdry A-type inclusion, and this later developed to a light basophilic, denser inclusion separated by a transparent zone from the marginated chromatin. Meanwhile the cytoplasm became less dense and lucent. The intranuclear transparent zone fused with the lucent cytoplasm at late stages of infection when the nuclear membrane was disrupted (Fig. 4). At the end of cellular deterioration, the nuclei or whole cells disintegrated, resulting in empty spaces in the sections. In moribund shrimp, most tissues and organs were heavily infected by the virus, showing severe multifocal necrosis leading to loss of cellular architecture.

\section{Ultrastructural cytopathology and virus morphology}

TEM observations confirmed the correspondence of intranuclear inclusions with the presence of a bacilliform virus. Based on the ultrastructural cellular changes in affected cuticular epidermal and stomach eplthelial cells that were derived from time-sequenced specimens, 4 distinct profiles of infected cells were distinguished in the pathogenesis of viral infection.

For Profile 1, the nuclei of infected cells were slightly hypertrophied, and most of the chromatin was marginated along the nuclear membrane in an interrupted layer (Fig. 5). The nucleolus and the chromatin were fused, causing the central area of the nucleus to become thin and homogeneous. No virions were noted, but viral envelope material was seen as

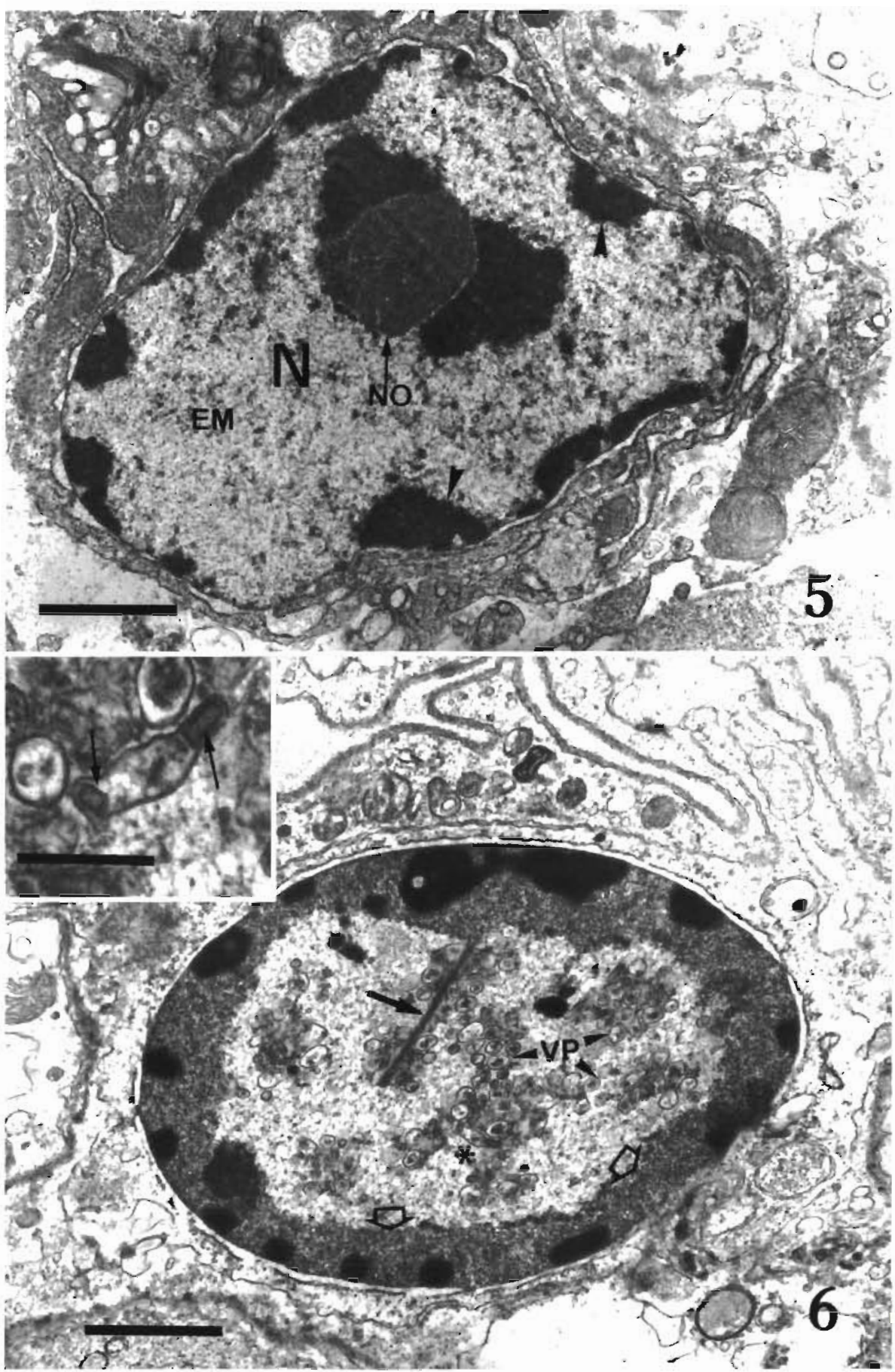

Fig. 5. Profile 1 of WSSV-infected cuticular epidermal cells. The nucleus $(\mathrm{N})$ is slightly hypertrophied and most of the chromatin is marginated along the nuclear border with a dense and interrupted appearance (arrowheads). Viral envelope material (EM) in fibrillar fragments is present in the rarefied central area. Note the remaining nucleolus (NO) and chromatun. Scale bar $=1.5 \mu \mathrm{m}$

Fig. 6. Profile 2 of WSSV-infected cuticular eprdermal cells. The marginated chromatin is transtormed into a dense ring-zone (blank arrows). The central virogenic stroma is less dense, vesicular in form, and shows many viral particles (VP) undergoing assembly Note a viral nucleosome (arrow) in the nucleus. Scale bar $=1.4 \mu \mathrm{m}$. Inset: Higher magnification of the viral particle (*) indicating 2 portions of a capsid separated at the ends (arrows) Scale bar $=340 \mathrm{~nm}$ 


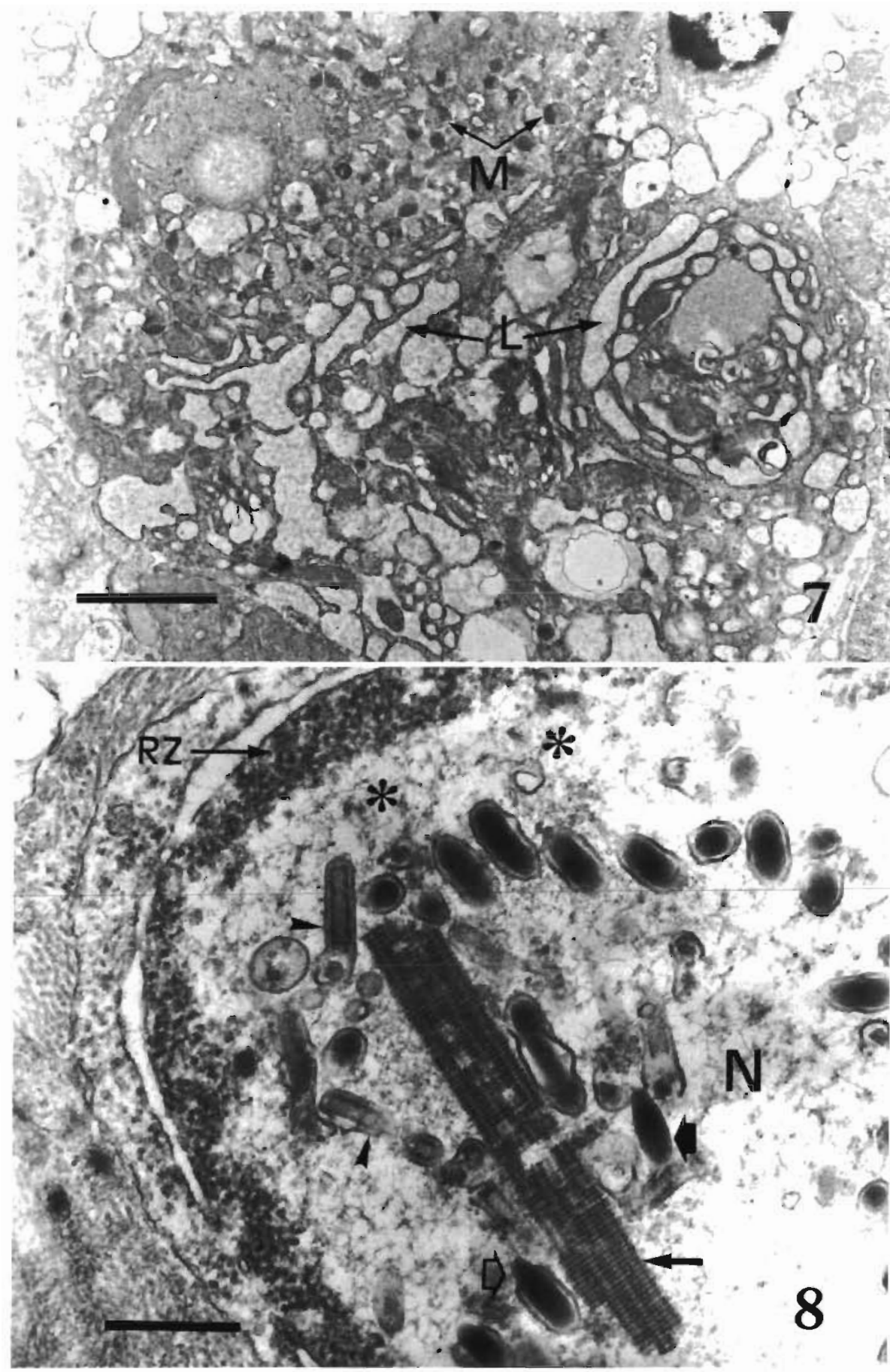

Fig. 7. Cytoplasmic changes in an WSSV-infected cuticular epidermal cell. Labyrinth (L) formed by a vacuolated network are present, and they extend over most areas of the cytoplasm resulting in an abnormal profile. Note the degraded mitochondria (M). Scale bar $=2.3 \mu \mathrm{m}$

Fig. 8. Profile 2 of WSSV-infected cuticular epidermal cell. In the nucleus (N), a viral nucleosome (arrow) is accompanied by immature viral particles whose envelopes are still open at one end (arrowheads). The viral nucleosome is composed of numerous repeating subunits in a stacked series. It shows 8 longitudinal electron-dense stripes and 4 lighter bands. An unenveloped nucleocapsid is obovate and electron-dense (bold arrow). One nucleocapsid is in the process of being enveloped (blank arrow). Note the transparent zone (asterisks) and ring-zone (RZ). Scale bar $=450 \mathrm{~nm}$ fibrillar fragments. In the cytoplasm, the endoplasmic reticulum (ER) was enlarged with abundant free ribosomes

For Profile 2, the nuclei were rounded due to gross hypertrophy. The very electron-dense marginated chromatin was embedded in a less electron-dense zone of granular material that formed a continuous dark layer (ring-zone or RZ) adjacent to the nuclear membrane (Fig. 6). The more electron-lucent central virogenic stroma contained distinct viral envelope material in membranous or vesicular form. In some cells, the central virogenic stroma was denser, with the appearance of numerous viral particles. A transparent zone was present between this dense virogenic stroma and the RZ (see Fig. 8), and this probably gave rise to the Cowdry A-type inclusions seen by light microscopy (LM). In this profile, a few mature and many immature virions were present in the central virogenic stroma. The deterioration of mitochondria was indicated by the transformation of the normal cristae into granules. In addition, membranous labyrinths commonly appeared. These were vacuolated networks covering large areas and they resulted in an abnormal cytoplasmic profile (Fig. 7).

A long, rod-shaped structure (LRS, $\approx 1900 \times 217 \mathrm{~nm}$ ) with numerous stacked, repeating subunits $(\geq 93)$ referred to as the viral nucleosome was often present singly in infected nuclei. Longitudinally, the entire LRS had a striped appearance with 8 electrondense and 4 electron-light bands (Fig. 8). It was notable that these viral nucleosomes were present in Profile 2, but absent in Profile 3.

For Profile 3, the RZ was absent, the nuclear membrane was disrupted, and the intranuclear transparent zone was fused with the electron-lucent cytoplasm. Hence, the central inclusion without an RZ appeared smaller than that in cells of Profile 2, and it was more electron-dense due to the presence of abundant, evenly distributed viral particles (Fig. 9). By contrast, the 
cytoplasm appeared electron-lucent. Most cellular organelles were abnormal, disintegrated into granules or reformed into membranous myelin-like structures. Both the nuclear and plasma membranes were partially disrupted.

For Profile 4, infected cells were completely damaged. The shedding of viral inclusions and cellular components resulted in many voids in the lesions (Fig. 10). These serial cytopathic effects illustrated that the virus was able to kill individual target cells. Tissue sections from moribund shrimp showed severe multifocal necrosis with the presence of many Profile 4 cells. This suggested that massive death of individual cells induced multifocal necrosis leading to the dysfunction of target organs and therefore death.

TEM observations showed that the bacilliform virus replicated, assembled and distributed withun nuclei without occluding protem. The enveloped virions were elliptical to short rod shaped in the long1tudinal section and round in the transverse section. The envelope was clearly trilamilar, consisting of 2 electron-opaque layers separated by 1 electron-lucent layer. Complete virions measured $305 \pm 30 \times$ $127 \pm 11 \mathrm{~nm}$, while capsids measured $271 \pm 25 \times 84 \pm 9 \mathrm{~nm}$ and the envelope $8 \pm 1 \mathrm{~nm}$ (Fig. 11). TEM examination confirmed the absence of viral particles in hepatopancreatocytes and epithelial cells of the midgut and the presence of viral particles in the target tissues ident1fied by normal histology. They were also found in haemocytes.

Based on cytopathological changes and viral particle development (from the appearance of partial elements, assembly, and particle maturation) seen in the virogenic stroma, 6 significant phases were nated in viral morphogenesis. In Phase I, viral nucleosomes appeared in affected nuclei prior to the appearance of viral particles, but coincidentally with the first appearance of

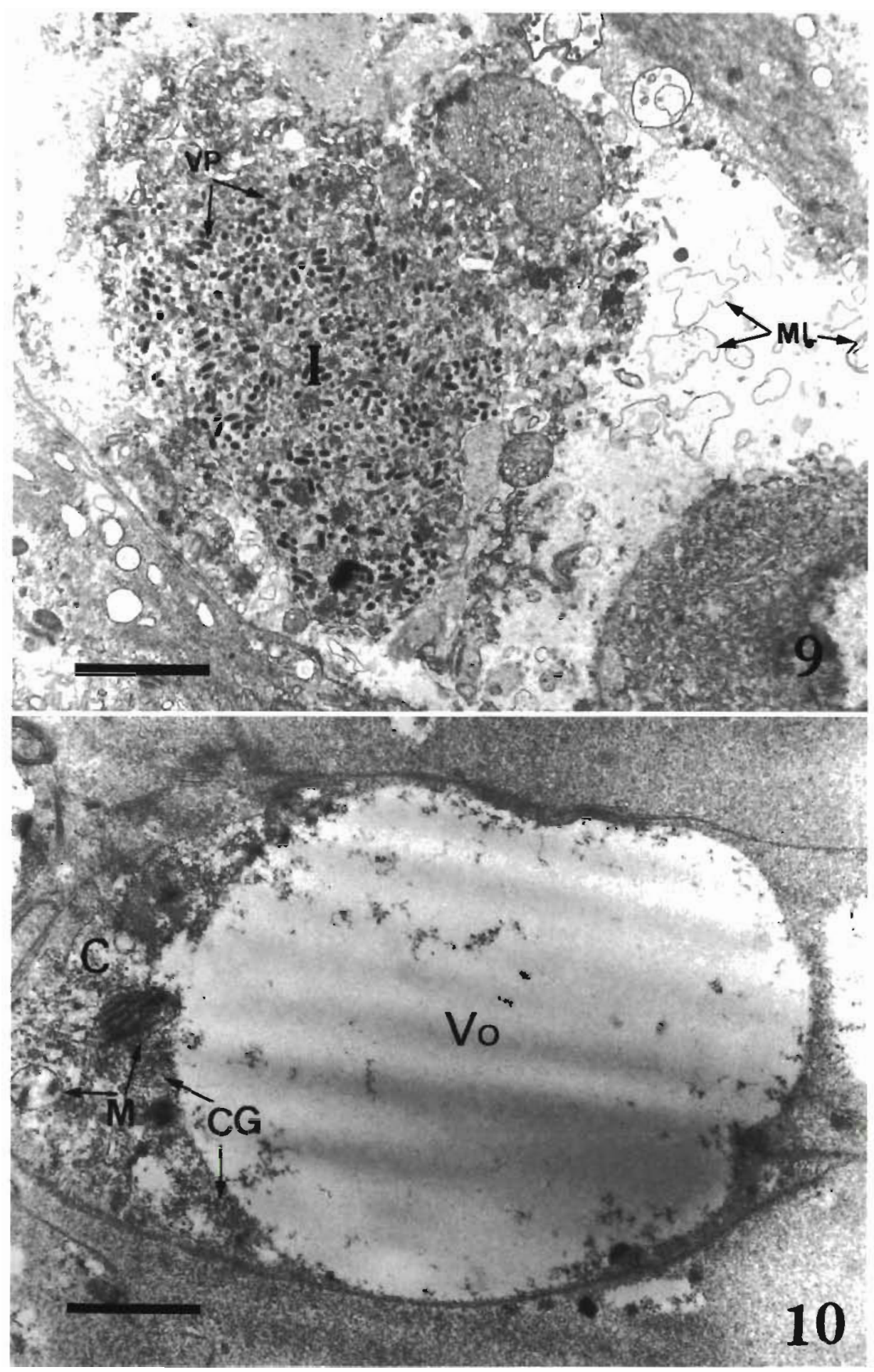

Fig. 9. Profile 3 of WSSV-infected cuticular epidermal cells There is no ring-zone and the nuclear membrane is disrupted. The electron-dense inclusion (I) contains abundant viral particles (VP) The cellular arganelles in the cytoplasm are disintegrated and appear as electron-lucent, cellular debris and membranous myelin-like structures (ML) Scale bar $=2.3 \mu \mathrm{m}$

Fig 10. Profile 4 of WSSV-infected stomach epithelial cells Sloughed nuclear elements and intranuclear viral inclusions have resulted in a void (Vo) with the cytoplasm still present (C) Note detenorated mitochondma (M) and cellular granules (CG) in the cytoplasm Scale bar $=1 \mu \mathrm{m}$ 


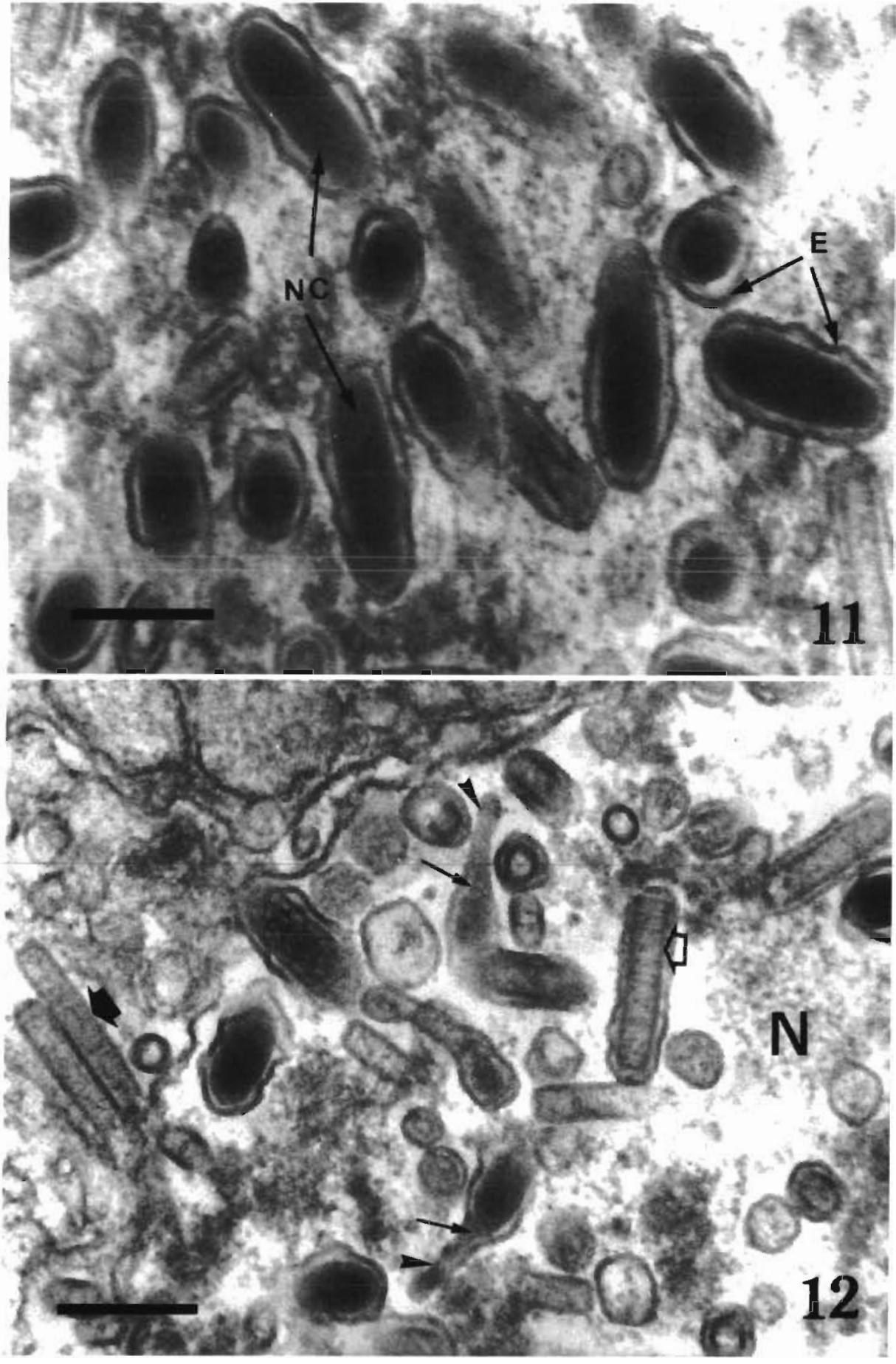

Fig. 11. Ultrathin section showing WSSV virions with a dense nucleoprotein core (NC) and a trilamilar envelope (E). They appear round in the transverse section and elliptical to short rod-shaped longitudinally. Scale bar $=200 \mathrm{~nm}$

Fig. 12. A WSSV-infected nucleus (N) of an epidermal cell showing some obovate viral particles with a long tail-like appendage (arrowheads) at one end enclosed by the viral envelope. The appendage's inner material (arrows) is separated from the viral nucleoprotein core. The nucleocapsid is composed of 12 to 14 rings of protein subunits in a stacked series (blank arrow). Note the unenveloped capsids assembled outside the viral envelopes (bold arrow). Scale bar $=230 \mathrm{~nm}$ fibrillar, viral envelope material. In Phase II, the fibrillar material formed into circular membranes that were soon filled with viral core material at the start of viral assembly (Fig. 6). In Phase III, less dense capsids appeared and gradually grew from one end towards the other, still open, extremity (Fig. 8). Occasionally, 2 half-capsids appeared within a single envelope (Fig. 6 inset). In Phase IV, the envelope enclosed the entire cylindrical capsid (Fig. 12), while the capsid resolved into 12 to 14 rings of protein subunits in a stacked series, and each capsid had 1 rounded and 1 squared extremity. The average size of the capsids for the immature viral particles was 313 by $50 \mathrm{~nm}$, and this was significantly longer and narrower than the capsids ( 271 by $84 \mathrm{~nm}$ ) of the mature virions. In Phase $\mathrm{V}$, at the late stage of the viral morphogenesis, the viral particle was obovate in shape with a long tail-like appendage enclosed by the viral envelope. The inner material of the appendage was separated from the viral nucleoprotein core (Fig. 12). Thereafter, the nucleocapsids became shorter, thicker and more electron-dense. In Phase VI, the final phase, the appearance of mature virions ranged between an elliptical shape and short rods, with complete and smooth envelopes, and electron-dense nucleocapsids (Fig. 11).

An alternative viral assembly mode was also observed in which unenveloped capsids assembled outside viral envelopes (Fig. 12) These free capsids became electron-dense and obovate in shape, and were subsequently wrapped with an envelope (Fig. 8). This suggests that the processes for viral nucleocapsid assembly, shortening and thickening, need not necessarily occur within a viral envelope.

Ultrastructural observations of cuticle and associated cuticular epidermis removed from the cephalo- 
thorax of shrimp, with and without white spot lesions, revealed that the epidermal cells were normally connected to the cuticle through cytoplasmic filaments, pore canals and ducts of tegumental glands. Cytoplasmic filaments were normal cellular organelles in cuticular epidermal cells. They traversed the cells and extended into the pore canals of the cuticle. Under TEM, these pore canals contained electron-dense substances (Fig. 13). However, infected epidermal cells, in addition to the pathological changes in the nuclei mentioned above, also showed the following cellular degeneration. First, the cytoplasmic filaments and pore canals were destroyed and electron-dense mass (EDM) appeared at the cell-cuticle interface. Second, there were many large vacuoles and much lysed cellular debris under the cuticle (Fig. 14). Measurements revealed that these vacuoles were identical in size (1 to $1.5 \mu \mathrm{m})$ and shape to the cavities seen by LM in wetmounts of white spot lesions (see Fig. 1c). This might indicate the association of vacuoles and cellular degeneration with the formation of white spots.

\section{DISCUSSION}

In terms of gross signs, histocytopathological effects and viral morphology, the virus described here from Malaysia is very similar to white spot syndrome virus previously reported from other countries (Chou et al. 1995, Huang et al. 1995, Wongteerasupaya et al. 1995, Durand et al. 1997). As such, the virus in this paper is designated as white spot syndrome virus (WSSV), and its presence is confirmed in the Malaysian shrimp farming systern.

In all cases, the virus did not infect the HEC and MEC of moribund shrimps, indicating that

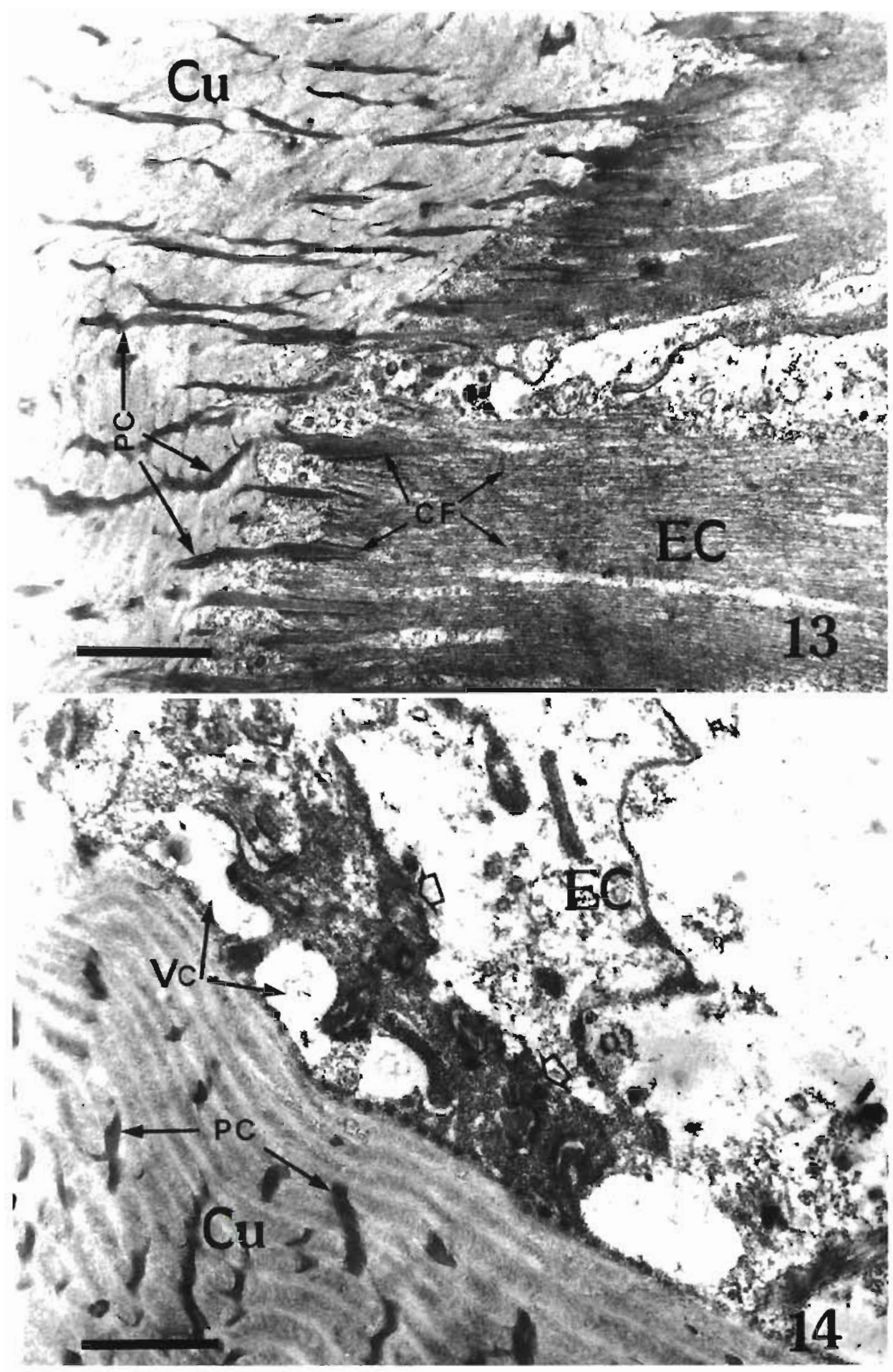

Fig. 13. Micrograph of a normal cuticular epidermal cells (EC) under the cuticle (Cu) Cytoplasmic fllaments (CF) extend from the epidermal cells to the pore canals (PC) in the cuticle. Transported cuticular material appears as electron-dense substances within the PC. Scale bar $=1.4 \mu \mathrm{m}$

Fig. 14. Micrograph of cuticular epidermal cells (EC) infected with WSSV. The cytoplasmic filaments and pore canals (PC) are disrupted. Lysed cellular debris and cuticular exudate are present as an accumulated, electron-dense mass (blank arrows) at the cell-cuticle interface, while many vacuoles (VC) also appear underneath the cuticle (Cu). Scale bar $=900 \mathrm{~nm}$ 
these tissues were refractory to the virus. Similar results were reported by Lo et al. (1997), who carried out a tissue distribution study of WSBV (now known as WSSV) in brooders of Penaeus monodon using in situ hybridization. However, our findings slightly differ with those of Lo et al. as they did not report the presence of infection in the musculature of the midgut as seen in the present study. This might be due to the higher susceptibility of cultured shrimp to infection compared to the wild-captured brooders which Lo and his colleagues studied. The high level of infection in haemocytes indicated that the viral infection was likely systemic. Thus, the surprising lack of HEC and MEC infection may have been due to the lack of appropriate viral receptors or to a disturbance of electrostatic interaction between the virus and the host cell surface (Voyles 1993). The shrimp hepatopancreas secretes a wide range of digestive enzymes and digestive juices in low pH (Van-Wormhoudt \& Bellon-Humbert 1994). This could have affected the electrostatic interaction of $\mathrm{HEC}$ and MEC, leading to a failure of infection. In the ovary, histopathological examination clearly revealed evidence of oocyte infection by WSSV, i.e. the presence of dense basophilic intranuclear inclusions. This result is consistent with recent reports that oocytes of WSSVinfected shrimp give a positive reaction for WSSV by in situ hybridization (Lo et al. 1997), and that intranuclear inclusion-like bodies can be seen in oocytes of WSSV infected shrimp (Mohan et al. 1997). These results suggest that vertical transmission of WSSV may occur from broodstock larvae via latently infected eggs. Histopathology showed that severely infected oocytes were probably unable to develop further and would probably die before maturation (see Fig. 2b). However, the hatchability of oocytes with light to very light (latent) infections still needs to be further investigated.

TEM observations showed that the entire LRS was several times larger than WSSV virions. LRS gradually decreased in length in Profile 2 as their subunits dispersed to the virogenic stroma, and they were absent in Profile 3. In other words, LRS were always accompanied by a small number of developing virions during the early stages of viral replication and assembly. Studies on other animals have reported that infections of several viruses show nucleosomal-like structures within infected host cells. According to these reports, viral DNA in early stages of infection is comprised of a DNA-protein complex rather than free DNA. These viral DNA-protein structures are based on repeating subunits containing DNA associated with histone proteins. These repeating structures, for example, those in bead form, are referred to as nucleosomes or minichromosomes (Tate \& Philipson 1979, Ben-Asher et al. 1982, Jeor et al. 1982). The organisation of intracellular viral DNA into a nucleosomes is an essential step in viral DNA synthesis (Ben-Asher et al. 1982, Bilimoria 1991). Based on this information, the LRS may comprise WSSV nucleosomes that are associated with early viral replication. Whatever their composition, they will be important structures in indicating the relationships amongst WSSV isolates and WSSV relationship to other viruses. Durand et al. (1997) reported a similar structure in WSSV infection, but they considered it to be an assembly of nucleocapsid precursors.

The molecular constituents of crustacean cuticles.are mainly chitin, calcium carbonate and protein. These cuticular substances are provided by the underlying epidermal cells and transported to the cuticle via cytoplasmic filaments and pore canals (Dennell 1960). Based on this knowledge, the electron-dense mass (EDM) seen in the cell-cuticle interface in WSSV infected shrimp could constitute accumulated cuticular substances such as calcium carbonate, proteins and chitin priming substances that have arisen due to blockage of cytoplasmic filaments and pore canals. TEM observations revealed that EDM also contained lysed cellular debris. EDM is assumed to be part of the white spots on the inner surface of the cuticle. The ultrastructure suggests that areas of affected cuticle would deteriorate due to transport blockage of maintenance substances. This might be why affected cuticle shows embedded, discolored spots under the light microscope, even after separation of the cuticle from the underlying epidermis and adhered EDM. In addition, wet-mount microscopy showed the presence of many scattered brownish dots within the white spots. The size and distribution pattern of the brownish dots were the same as those of normal tegumental gland pores (Fig. 1c). This suggested that necrosis and melanization of tegumental glands might also occur with viral infection and change the color of white spots. From the results, it can be concluded that the white spots are compound structures composed of melanized material from tegumental glands, deteriorated opaque cuticular lesions embedded in the cuticle, underlying lysed cellular debris and blocked cuticular exudates deposited at the cell-cuticle interface. However, in spite of this, the white spots are mainly embedded in the shell, since they are still visible after the underlying tissues have been scraped off from the inner surface of the shell. Under the microscope, the resulting spots were yellowish-brown and opaque, although they appeared to be chalky white to the naked eye.

Acknowledgements. The authors thank the International Development Research Centre (IDRC, Canada), Universiti Putra Malaysia short-term research grant (No. 50213), and Intensification of Research in Priority Areas (IRPA, Malaysia) research grant (No. 51216) for funding this study. The authors' appreciation also goes to Drs Lee Kok Leong and Tan Lee Tung for their comments and suggestions. 


\section{LITERATURE CITED}

Bell TA, Lightner DV (1988) A handbook of normal penaeid shrimp histology. World Aquaculture Society, Baton Rouge, LA

Ben-Asher E, Bratosin S, Aloni Y $\{1982\}$ Intracellular DNA of the parvovirus minute virus of mice is organised in a minichromosome structure. J Virol 41 (3):1044-1054

Bilimoria SL (1991) The biology of nuclear polyhedrosis viruses. In: Kurstak E (ed) Viruses of invertebrates. Marcel Dekker Inc, New York, p 1-72

Chou HY, Huang CY, Wang CH, Chiang HC, Lo CF (1995) Pathogenicity of a baculovirus infection causing white spot syndrome in cultured penaeid shrimp in Taiwan. Dis Aquat Org 23:165-173

Dennell R (1960) Integument and exoskeleton. In: Waterman $\mathrm{TH}$ (ed) The physiology of crustacea. Academic Press, New York, p 449-472

Durand S, Lightner DV, Redman RM, Bonami JR (1997) Ultrastructure and morphogenesis of white spot syndrome baculovirus (WSSV). Dis Aquat Org 29:205-211

Flegel TW (1997) Special topic review: major viral diseases of the black tiger prawn (Penaeus monodon) in Thailand. World J Microbiol Biotech 13:433-442

Flegel TW, Boonyaratpalin S, Withyachumnamkul B (1996) Current status of research on yellow-head virus and white-spot virus in Thailand. In: LeRoy Cresswell R (ed) Book of abstracts. World Aquaculture ' 96 held in Bangkok, Thailand, Jan 29-Feb 2, 1996. World Aquaculture Society, Harbor Branch Oceanographic Institute, Ft Pierce, FL, p $126-127$

Hayat MA (1986) Basic techniques for transmission electron microscopy. Academic Press, Inc, San Diego, CA

Huang J, Song XL, Yu J, Yang CH (1995) Baculoviral hypodermal and hematopoietic necrosis - study on the pathogen and pathology of the explosive epidemic disease of shrimp. Mar Fish Res 16(1):1-10

Jeor SS, Hall C, Mcgaw C, Hall M (1982) Analysis of human cytomegalovirus nucleoprotein complexes. J Virol 41(1): 309-312

Kasornchandra J, Boonyaratpalin S (1996) Red disease with white patches or white spot disease in cultured penaeid shrimp in Asia. Asian Shrimp News, 3rd Quarter, No. 27, Asian Shrimp Culture Council, Bangkok

Kasornchandra J, Boonyaratpalin S (1998) Primary shrimp cell culture: applications for studying white spot syndrome virus (WSSV). In: Flegel TW (ed) Advances in shrimp biotechnology. National Center for Genetic Engineering and Biotechnology, Bangkok, p 273-276

Lightner DV (1996) A handbook of pathology and diagnostic procedures for diseases of penaeid shrimp. World Aquaculture Society, Baton Rouge, LA

Lo $\mathrm{CF}$, $\mathrm{Ho} \mathrm{CH}_{1}$ Chen $\mathrm{CH}$, Liu KF, Chiu YL, Yeh PY, Peng SE, Hsu HC, Liu HC, Chang CF, Su MS, Wang CH, Kou GH

Editorial responsibility: Timothy Flegel,

Bangkok, Thailand
(1997) Detection and tissue tropism of white spot syndrome baculovirus (WSBV) in captured brooders of Penaeus monodon with a special emphasis on reproductive organs. Dis Aquat Org 30:53-72

Mohan CV. Sudha PM, Shankar KM, Hegde A. (1997) Vertical transmission of white spot baculovirus in shrimps - a possibility? Curr Sci 73(2): 109-110

Shariff M (1995) Fish health: an odyssey through the AsiaPacific region. Special publication of Universiti Pertanian Malaysia, Serdang, Malaysia

Takahashi Y, Itami T, Kondom M, Maeda M, Fujii R, Tomonaga S. Supamattaya K, Boonyaratpalin S (1994) Electron microscopic evidence of bacilliform virus infection in Kuruma shrimp (Penaeus japonicus). Fish Pathol 29: $121-125$

Tate VE, Philipson L (1979) Parental adenovirus DNA accumulates in nucleosome-like structures in infected cells. Nucleic Acids Res 6:2769-2785

Van-Wormhoudt A, Bellon-Humbert C (1994) Crustacean farming: The biological basis. In: Barnabé G (ed) Aquaculture-biology and ecology of cultured species. Ellis Horwood, New York, p 177-223

Voyles BA (1993) The biology of viruses. Mosby, St. Louis, $\mathrm{MO}$

Wang CH, Lo CF, Leu JH, Chou CM, Yeh PY, Chou HY, Tung MC, Chang CF, Su MS, Kou GH (1995) Purification and genomic analysis of baculovirus associated with white spot syndrome (WSBV) of Penaeus monodon. Dis Aquat Org 23:239-242

Wang YG, Hassan MD, Shariff M, Saad MZ (1996) Cytopathological study of the systemic ectodermal and mesodermal baculovirus (SEMBV) infection in cultured black tiger shrimp Penaeus monodon in Penınsular Malaysia. In the proceedings of 6 th Scientific Conference Electron Microscopy Society Malaysia held in Petaling Jaya, Selangor, Oct. 26-27, 1996. University Malaya and Electron Microscopy Society Malaysia, Kuala Lumpur

Wang YG, Hassan MD. Shariff M (in press) Management of shrimp diseases in Malaysia. In: Proceedings of the Seminar on Sustainable Development of Mariculture Industry in Malaysia held in Kuala Lumpur, July 30-31, 1997. Maritime Institute of Malaysia, Kuala Lumpur

Wongteerasupaya C, Vickers JE, Sriurairatana S, Nash GL Akarajamorn A, Boonsaeng V, Panyim S, Tassanakajon A, Withyachumnarnkul B, Flegel TW (1995) A non-occluded, systemic baculovirus that occurs in cells of ectodermal and mesodermal origin and causes high mortality in the black tiger prawn Penaeus monodon. Dis Aquat Org 21:69-77

Wongteerasupaya $C$, Wongwisansri S, Boonsaeng V, Panyim S, Pratanpipat P, Nash GL, Withyachumnarnkul B, Flegel TW (1996) DNA fragment of Penaeus monodon bac ulovirus PmNOBII gives positive in situ hybridization with white-spot viral infections in six penaeid shrimp species. Aquaculture 143:23-32

Submitted: January 29, 1998; Accepted: July 16, 1999 Proofs received from author(s): November 26, 1999 